\title{
PROFIL KELEMBAGAAN PETANI DALAM PROGRAM REVITALISASI SEKTOR PERTANIAN DI KABUPATEN SITUBONDO
}

\section{PROFILE OF FARMER'S INSTITUTION IN THE REVITALIZATION OF AGRICULTURE SECTOR PROGRAM AT DISTRICT OF SITUBONDO}

Edy Sutiarso*), R.A. Ediyanto*), Syamsul Hadi,*), dan Kahar Haerah**)

*) Dosen Program Studi Agrbisnis Feperta UM Jember

**) Dosen Program Studi Ilmu Pemerintahan FISIP UM Jember

Email: esutiarso@yahoo.com

\begin{abstract}
ABSTRAK
Program Revitalisasi Sektor Pertanian telah dilaksanakan di Kabupaten Situbondo sejak beberapa tahun yang lalu, tetapi kontribusi sektor pertanian terhadap Produk Dometik Regional Bruto berdasarkan lapangan usaha periode 2011-2016 mengalami penurunan cukup signifikan. Oleh karena itu, tujuan tulisan ini adalah mengkaji profil kelembagaan petani dalam pelaksanaan program tersebut dikaitkan dengan kinerja sub sektor pertanian tanaman pangan. Metode penelitian yang digunakan adalah metode deskriptif kualitatif melalui teknik survei dan untuk menjawab tujuan penelitian, maka digunakan analisa desktriptif dengan penyajian model tabel frekuensi. Hasil penelitian menunjukkan bahwa Rata-rata kondisi profil kelembagaan petani di daerah penelitian dalam kondisi cukup baik ditinjau dari aspek aspek kualitas SDM, Lamanya berdiri, jenis dan status kelembagaan, bentuk organisasi, dan pola hubungannya dengan petani tanaman pangan. Dampak kondisi profil tersebut tidak banyak berpengaruh nyata terhadap peningkatan kinerja sub sektor tanaman pangan antara sebelum dan sesudah pelaksanaan program revitalisasi pertanian.
\end{abstract}

Kata Kunci: Profil, Revitalisasi, dan Kinerja

\begin{abstract}
Agricultural Sector Revitalization Program has been implemented in Situbondo Regency since several years ago, but the contribution of agriculture sector to Gross Regional Dynamic Product based on business field in 2011-2016 period has decreased significantly. Therefore, the purpose of this paper is to assess the institutional profile of farmers in the implementation of the program is related to the performance of food crops sub-sector. The research method used is descriptive qualitative method through survey technique and to answer the purpose of research, hence used descriptive analysis with presentation of model of frequency table. The results showed that the average condition of institutional profile of farmers in the research area is in good condition in terms of aspects of quality of human resources, duration of standing, type and institutional status, organizational form, and relationship pattern with food crop farmers. The impact of the condition of the profile did not significantly affect the performance of the food crop sub-sector between before and after the implementation of the agricultural revitalization program.
\end{abstract}

Keywords: Profile, Revitalization, and Performance

\section{PENDAHULUAN}

Fenomena menurunnya kinerja sektor pertanian secara nasional sebagimana diuraikan di atas, juga dialami di Kabupaten Situbondo Propinsi Jawa Timur. Kontribusi/peranan sektor pertanian mengalami penurunan selama lima tahun terakhir berturut-turut yaitu pada tahun 2010 sebesar $35.82 \%$, tahun 2011 sebesar 35,45\%, tahun 2012 sebesar $35,79 \%$, tahun 2013 sebesar 35,94\%, tahun 2014 sebesar 36,32\%, tahun 2015 sebesar 36,24\%, dan tahun 2016 sebesar $35,54 \%$. Berdasarkan Laporan Kinerja Pememerintah Kabupaten Situbono tahun 
2016 bahwa sektor perdagangan, hotel \& Restoran mengalami pertumbuhan yang signifikan dan menjadi penyumbang PDRB tertinggi serta diikuti oleh sektor pertanian, industri pengolahan dan sektor jasa (BPS Kabupaten Situbondo, 2017). Gambaran penurunan kontribusi sektor pertanian terhadap PDRB dimaksud dapat ditunjukkan oleh Gambar 1.1.

Penurunan kontribusi/peranan sektor pertanian disebabkan oleh semakin banyaknya petani yang beralih profesi ke sektor lain karena sektor pertanian semakin tidak memberikan keuntungan yang banyak bagi petani. Tentunya sangat dibutuhkan peranan Pemerintah untuk membantu mengurai permasalahan-permasalahan yang dihadapi para petani mulai hulu sampai hilir seperti penyediaan bibit pertanian yang berkualitas, terjaminnya stok pupuk pada saat dibutuhkan, jaminan harga yang stabil serta jaminan pemasaran.

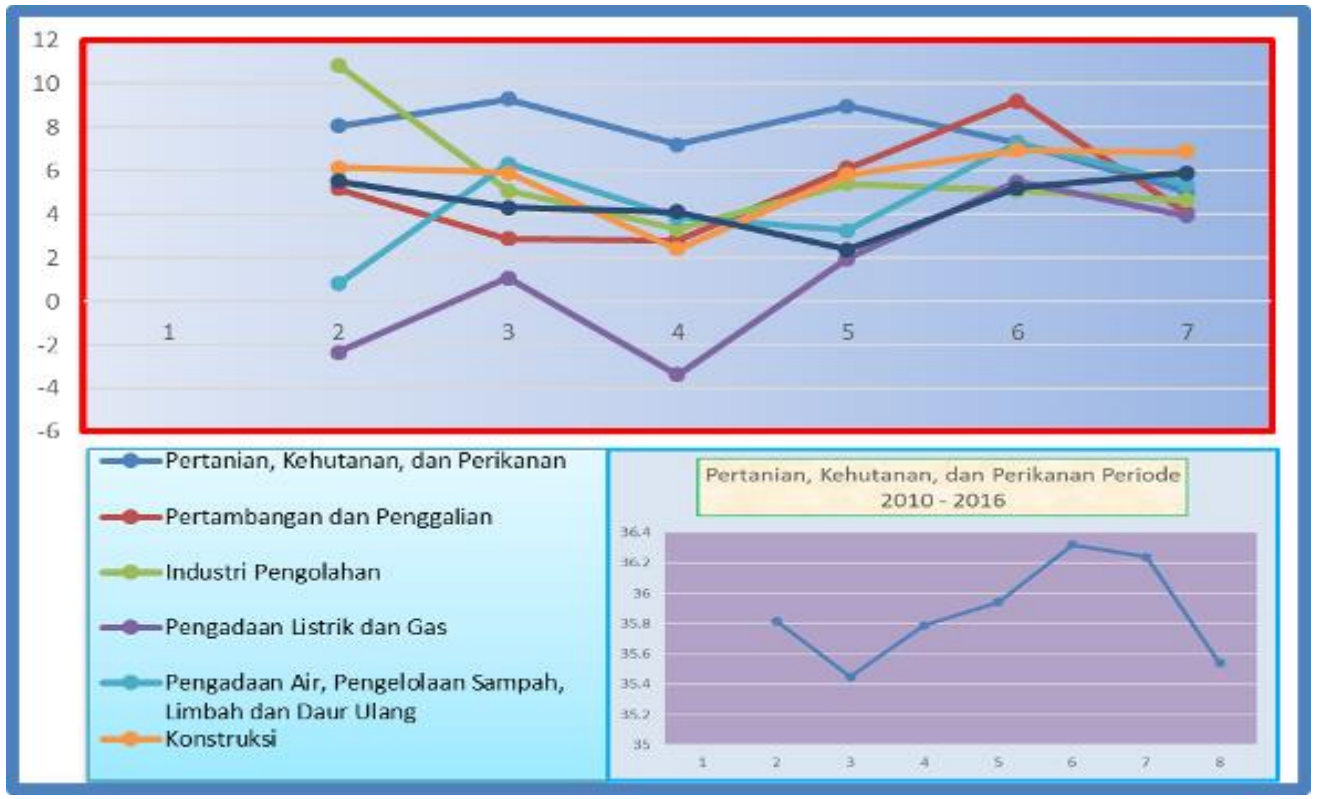

Gambar 1.1. Laju Pertumbuhan Kontribusi Sektor Usaha Terhadap Pembentukan PDRB Kabupaten Situbondo Periode 2011 -2016 Berdasarkan Harga Berlaku (Persen) (Sumber: BPS Kabupaten Situbondo, 2017)

Berdasarkan Gambar 1.1 di atas dapat dikatakan bahwa Kabupaten Situbondo menurut lapangan usaha/sektoral sedang mengalami pergeseran peran dan struktur perekonomian dari sektor primer (sektor Pertanian dan sektor Pertambangan \& Penggalian) ke sektor sekunder (sektor Industri Pengolahan, sektor Listrik, Gas \& Air Bersih, sektor Konstruksi) dan tersier (Sektor Perdagangan, Hotel \& Restoran; Pengangkutan \& Komunikasi;
Keuangan, Persewaan \& Jasa Perusahaan; Jasa-Jasa). Apabila dilihat besarnya penurunan produksi untuk beberapa komoditi pertanian di Kabupaten Situbondo dalam dekade terkahir ini, masing-masing sebagai berikut: produksi tanaman padi sawah turun $9,19 \%$, tanaman padi gogo turun sebesar 42,60\%, tanaman jagung turun $28,79 \%$, tanaman ubi kayu turun $45,51 \%$, tanaman acang tanah turun 70,53\%, tanaman kacang hijau turun $71,57 \%$ dan 
tanaman kedelai menunjukkan penurunan sebesar 58,25\%. Apabila dilihat dari luas panen masing-masing komoditi, beberapa komoditi mengalami penurunan, yaitu luas panen padi sawah turun $6,19 \%$, padi gogo turun $30,21 \%$, ubi kayu turun 11,23 $\%$, jagung turun $15,78 \%$, dan kacang tanah turun $33,75 \%$, kacang hijau turun $71,79 \%$ dan kedelai turun 76,92\%.

Menurut data BPS Kabupaten Situbondo (2017) bahwa di Kabupaten Situbondo memiliki banyak kelembagaan petani pada tahun 2016 antara lain HIPPA ada 136 unit (bertambah 15 unit dari tahun 2015), kelompok tani ada 685 unit, Pusat Pelatihan Pertanian Pedesaan dan Swadaya ada 6 unit. Berdasarkan komoditas unggulan dibagi beberapa macam, yaitu: Tanaman pangan memiliki 681 kelompok tani (134 Gapoktan), hortikultura memiliki 595 kelompok tani (111 gapoktan), perkebunan dan kehutanan memiliki 610 kelompok tani (126 gapoktan). Demikian banyaknya jumlah kelompok tani dan gabungan kelompok tani tersebut sejatinya kinerja sektor pertanian lebih meningkat. Namun yang terjadi khsusunya pada sub sentor tanaman bahan pangan adalah kinerjanya cenderung menurun.

Secara teori banyak tidaknya kelembagaan petani di suatu daerah dapat berimplikasi positif terhadap tingkat kinerja sektor pertanian. Namun fakta di lapangan menunjukkan kondisi yang berbeda, dimana kinerja sektor pertanian khususnya sub sektor tanaman pangan di Kabupaten Situbondo justru dalam kondisi perkembangan yang mengkuatirkan dalam jangka panjang. Oleh karena itu, menjadi sangat penting untuk dilakukan kajian mendalam tentang profil kelembagaan petani hubungannya dengan pertumbuhan kinerja sub sektor pertanian tanaman bahan pangan di Kabupaten Situbondo. Oleh karena itu, tujuan penelitian ini adalah mengkaji profil kelembagaan petani dalam pelaksanaan program tersebut dikaitkan dengan kinerja sub sektor pertanian tanaman pangan.

\section{METODE PENELITIAN}

\section{Jenis dan Metode Penelitian}

Jenis penelitian ini adalah penelitian deskriptif kuantatif dan kualitatif, yaitu penelitian yang bertujuan untuk mencari fakta dengan interpretasi yang tepat (Nasir, 1985). Sementara itu, metode yang digunakan dalam penelitian ini adalah metode survei (Singarimbun, 1987). Dipilihnya metode survei karena jumlah populasi sasaran jenis kegiatan terlampau banyak dan tersebar di beberapa wilayah kecamatan, dan dipilihnya evaluasi formatif ini atas dasar pertimbangan bahwa obyek penelitian adalah sebuah program yang masih sedang berlangsung sejak tahun 2006.

\section{Penentuan Waktu dan Lokasi Penelitian}

Penelitian ini telah dilakukan pada tahun 2017 di 17 wilayah kecamatan Kabupaten Situbondo dengan 20 desa sampel yang ditentukan secara purposive sampling atas pertimbangan bahwa kabupaten tersebut menjadi salah satu dari delapan kabupaten di Jawa Timur yang tergolong daerah rawan pangan. Selain itu lokasi penelitian secara institusional dilakukan di Dinas Ketahanan Pangan \& Hortikultura dan Dinas Pertanian Kabupaten Situbondo, Bappekab. Situbondo, dan BPS Situbondo 


\section{Sumber, Jenis dan Teknik Pengumpulan Data}

Berdasarkan sumbernya bahwa data yang dikumpulkan dalam penelitian ini meliputi data primer dan data sekunder. Data primer diperoleh dari kelompok tani, gabungan kelompok tani, dan kelembagan petani pendukung lainnya seperti BRI-UD, HIPPA, KUD, Koperasi, Mantri Pertanian Kecamatan, BPP-PPL, dan Pamong Tani melalui teknik pengumpulan data gabungan dari beberapa teknik pengumpulan data yang saling melengkapi yaitu meliputi: FGD, Indepth Interview dan observasi. Adapun data sekunder diambil dari sumber yang terkait dengan penelitian ini secara institusional sebagai informasi dasar guna memulai penggalian data primer secara convenience sampling (Singarimbun, 1987)

\section{Teknik Analisis Data}

Uji validitas digunakan untuk mengukur sah atau valid tidaknya suatu instrumen dalam kuisioner. Suatu kuesioner dinyatakan valid apabila pertanyaan pada kuesioner mampu untuk mengungkapkan sesuatu yang akan diukur. Pengujian instrumen penelitian ini dengan cara menghitung korelasi menggunakan teknik korelasi Pearson dengan tarif signifikan 5\%. Selanjutnya uji Reliabilitas untuk mengetahui sejauh mana hasil pengukuran dapat dipercaya yang dilakukan dengan bantuan SPSS yang merupakan fasilitas untuk mengukur reliabilitas, dengan uji statistik cronbach alpha $(\alpha)$ suatu variabel dikatakan reliable jika memiliki cronbach alpha > 0.60 (Ghozali, 2005). Guna menjawab tujuan penelitian digunakan analisa desktriptif dengan penyajian model tabel frekuensi dan analisis uji beda rata-rata Paired Sample t-test untuk mengetahui kinerja sub sektor pertanian tanaman pangan sebelum dan sesudah pelaksanaan Program Revitalisasi Pertanian.

\section{HASIL DAN PEMBAHASAN}

Profil kelembagaan petani merupakan kondisi eksisting organisasi secara fisik yang merupakan gambaran bentuk kapasitas dan kemampuan untuk menjalankan fungsi dan tugasnya dalam pencapaian tujuan-tujuan organisasi. Profil yang akan dibahas dalam kajian ini meliputi aspek kualitas SDM, Lamanya berdiri, jenis dan status kelembagaan, bentuk organisasi, dan pola hubungannya dengan petani tanaman pangan. Pada Tabel 1 di bawah menunjukkan bahwa kelembagaan petani sudah berdiri dan eksis rata-rata sejak 14,80 tahun lalu dengan kisaran antara 1 s.d 46 tahun. Sebuah rata-rata usia yang memasuki masa remaja dimana mobilitas dan dinamikanya cukup akseleratif dalam menjalankan fungsinya. Lembaga keuangan seperti BRI unit, Koperasi, KUD, BPP-PPL dan HIPPA serta Gapoktan/ Kelompoktani merupakan kelembagaan petani yang usianya tergolong di atas remaja bahkan sudah tergolong dewasa dan matang. Sebab semakin lama umur lembaha berdiri, maka semakin banyak pengalaman yang dialami dan semakin baik pula tingkat manajerialnya.

Nurwati $d k k$.

membuktikan dalam risetnya kaitannya umur lembaga dan kinerja Bank Umum Syariah (BUS) di Indonesia. Dari hasil penelitian menunjukan bahwa semakin lama umur perusahaan, semakin baik kinerjanya, ini menunjukan bahwa 
pengalaman merupakan akumulasi pengetahuan yang dapat menjadikan kinerja perusahaan lebih baik, sebagaimana beberapa penelitian sebelumnya (Ericson dan Pakes, 1995; Coad et al., 2011; Kipesha, 2013 dalam Nurwati $d k k$. , 2014). Berbeda dengan penelitian Loderer \& Waelchli (2010, 2011) dalam Nurwati dkk. (2014yang menunjukan bahwa perusahaan semakin tua, kinerja mereka memburuk. Adanya perbedaan ini dapat disebabkan karena adanya perbedaan industri yang diteliti dan adanya faktor lain yang berpengaruh terhadap kinerja BUS.

Selanjutnya pada aspek kualitas Sumberdaya Manusia (SDM) pengurus kelembagaan petani dapat diukur dari tingkat pendidikan formal lembaga. Hasil kajian ini sebagaimana yang ditunjukkan Tabel 3.1 pula dapat diungkapkan bahwa rata-rata tingkat pendidikan formal untuk responden pengurus lembaga tergolong berpendidikan tinggi (rata-rata lama mengenyam pendidikan 12,41 tahun), meskipun sebanyak $67,05 \%$ hanya lulusan Sekolah Dasar. Hal ini disebabkan karena terdapat 23,86\% yang

Tabel 1. Profil Kelembagan Petani di Kabup lulusan sarjana strata-1 dan sebanyak $1,14 \%$ lulusan strata-2, sementara atau tamat sekolah lanjutan tingkat pertama dan atas sebesar $(9,09 \%)$. Sementara ratarata tingkat pendidikan responden petani tergolong berpendidikan sedang (lama mengenyam pendidikan formal 10,43 tahun), dan yang berpendidikan tinggi (sarjana stara-1 sebanyak 10,81\%) dan yang berpendidikan rendah hanya sebanyak $18,42 \%$.

Kondisi tingkat pendidikan kedua responden tersebut akan berpengaruh terhadap tingkat pengetahuan, cara berpikir, bersikap, dan bertindak lebih rasional dan proporsional khususnya dalam menjalankan roda organisasi. Meskipun demikian pengetahun tersebut bukan hanya diperoleh dari jenjang pendidikan formal, tetapi juga diperoleh dari pendidikan non formal. Hal ini sesuai dengan pendapat Soekartawi (1998) bahwa tingkat pendidikan formal merupakan salah satu faktor yang mempengaruhi seseorang untuk berfikir ke arah yang lebih rasional, dan selebihnya dipengaruhi oleh faktor lainnya.

\begin{tabular}{|c|c|c|c|}
\hline No & Uraian Profil Kelembagaan & Frekuensi (Org) & Persentase $(\%)$ \\
\hline A. & \multicolumn{3}{|c|}{ Lamanya Berdiri (Tahun) } \\
\hline 1 & $\leq 10$ & 38 & 43.18 \\
\hline 2 & 11 s.d. 20 & 34 & 38.64 \\
\hline \multirow[t]{2}{*}{3} & $\geq 21$ & 16 & 18.18 \\
\hline & Jumlah & 88 & 100 \\
\hline B. & \multicolumn{2}{|c|}{ Kualitas SDM Pengurus/Pendidikan (Tahun) } & \\
\hline 1 & $\leq 6$ & 59 & 67.05 \\
\hline 2 & 7 s.d 12 & 8 & 9.09 \\
\hline \multirow[t]{2}{*}{3} & $\geq 13$ & 21 & 23.86 \\
\hline & Jumlah & 88 & 100 \\
\hline C. & \multicolumn{2}{|c|}{ Jenis Kelembagaan Lokal } & \\
\hline 1 & Kelompok tani dan Gapoktan & 41 & 46.59 \\
\hline 2 & Lembaga Keuangan & 17 & 19.32 \\
\hline \multirow[t]{3}{*}{3} & BPP - PPL dan Dispertahorti & 13 & 14.77 \\
\hline & HIPPA /P3A & 17 & 19.32 \\
\hline & Jumlah & 88 & 100 \\
\hline
\end{tabular}




\begin{tabular}{cccc}
\hline D. & Profit & Bentuk Organisasi & \\
1 & & 17 & 19.32 \\
2 & Non Profit (Nirlaba) & 71 & 80.68 \\
& Jumlah & $\mathbf{8 8}$ & $\mathbf{1 0 0}$ \\
\hline E. & Status Kelembagaan & & \\
1 & Pemerintah & 14 & 15.91 \\
2 & Swasta & 74 & 84.09 \\
3 & BUMN-BUMD & 0 & 0.00 \\
& Jumlah & $\mathbf{8 8}$ & $\mathbf{1 0 0}$ \\
\hline F. & Bentuk Hubungan dengan petani tanaman pangan \\
1 & Kemitran/Pendamping & 58 & 65.91 \\
2 & Kreditor & 17 & 19.32 \\
3 & Pembina/Pendamping & 13 & 14.77 \\
& Jumlah & $\mathbf{8 8}$ & $\mathbf{1 0 0}$ \\
\hline
\end{tabular}

Sumber: Data Primer Diolah

Tabel 1 di atas juga menggambarkan bahwa kelembagaan petani di daerah penelitian berdasarkan jenisnya dapat dibagi menjadi empat, yaitu: Kelompok tani dan Gapoktan, Lembaga Keuangan, BPP - PPL dan Dispertahorti, dan HIPPA /P3A. jenis yang petama adalah organisasi yang langsung berhubungan dengan anggota kelompok tani dan stakeholders yang terkait. Jumlah sampel jenis kelompok tersebut sebanyak $46,59 \%$ yang merupakan bagian dari jumlah kelompok tani dan gapoktan secara keseluruhan yang mencapai 685 unit kelompok tani dan 134 Gapoktan di Kabupaten Situbondo. Adapun jenis kelompok lembaga keuangan terdiri dari KUD, BRI-UD, BPR, dan koperasi simpan pinjam yang mencapai $19,32 \%$. Tidak semua lembaga keuangan yang ada dapat melayani petani untuk mendukung pada kegiatan usahataninya, kecuali BRI dan KUD meskipun terbatas. Sementara jenis kelompok BPP, PPL, dan THLTBPP serta Dinas Ketahanan Pangan dan Hortikultura merupakan lembaga yang memiliki kewajiban untuk membina, membimbing, mensupervisi, mengendalikan dan mengevaluasi kinerja kelembagaan petani secara langsung.
Jenis kelembagaan petani seperti HIPPA merupakan lembaga yang wajib melayani petani dalam penyediaan kebutuhan air irigasi.

Berdasarkan persepsi anggota kelompok tani bahwa sebanyak 68,42\% responden petani menyatakan kinerja kelembagaan petani kurang baik. Hal ini disebabkan frekuensi Kelembagaan Petani (PPL, HIPPA, dan THL-TBPP) dalam memberikan dampingan/ penyuluhan/supervisi kepada petani setiap musim relatif rendah, bahkan ada sebagian kecil responden yang menyatakan tidak pernah merasakan kehadiran lembaga dimaksud. Rendahnya kinerja penyuluh tersebut menurut Saptana et al. (2013) disebabkan oleh bebera hal, yaitu: aspek struktur kelembagaan, materi dan program penyuluhan, sistem penunjang, hingga kualifikasi dan penyebaran sumber daya manusia penyuluh. Saat ini kuantitas penyuluh mulai berkurang karena sebagian sudah memasuki masa purna tugas (pensiun) sementara pengangkatan penyuluh PNS tetap terbatas, status penyuluh THL masih belum jelas, dan eksistensi penyuluh swadaya juga masih belum optimal. Perbaikan kualitas 
penyuluh dapat dilakukan melalui penerapan prinsip.

Sementara itu, Tabel 1 di atas juga menggambarkan profil kelembagaan pada aspek bentuk organisasi yang terbagi dua kelompok, yaitu kelompok lembaga profit $(19,32 \%)$ dan Non Profit $(80,68 \%)$. Kondisi ini merupakan kondisi kurang proporsional jika ditinjau dari segi jumlah kegiatan usahatani yang memerlukan banyak kebutuhan modal usahatani. Idealnya keberadaan lembaga yang berorientasi profit minimal berjumlah $30 \%$ di suatu kawasan. Adapun berdasarkan status kelembagaan, maka kelembagaan petani di daerah penelitian dibagi menjadi dua status, yaitu: pemerintah dan swasta. Kelembagaan yang berstatus pemerintah hanya sebanyak $15,91 \%$ dan sisanya berstatus swasta. Kondisi ini sangat ideal dalam rangka mendukung terhadapo kinerja sub sektor tanam,an pangan.

Berdasarkan bentuk pola hubungan dengan petani tanaman pangan, kelembagaan petani di daerah penelitian dibagi menjadi 3 kelompok, yaitu: pola Kemitraan/Pendamping (65,9\%), Kreditor (19,32\%), dan Pembina/Pendamping (14,77\%). Apabila dilihat dari jumlah kelompok lembaga yang memiliki pola hubungan kemitraan/pendamping, idealnya kinerja sub sektor tanaman pangan di daerah penelitian kecenderungan mengalami peningkatan. Meskipun jumlah keberadaan lembaga kreditor kurang dari $30 \%$, tetapi kelompok pendamping dan pembina jumlahnya sangat dominan. Namun demikian fakta di lapangan menunjukkan kondisi yang berbeda.

Pada Tabel 2 di bawah menunjukkan hasil evaluasi dampak pelaksanaan program revitalisasi pertanian dikaitkan dengan kondisi profil kelembagaan petani di daerah penelitian. Hasil uji beda rata-rata t-test terhadap jumlah produksi pertanian antara sebelum dan sesudah pelaksanaan program tidak berbeda nyata pada taraf nyata $10 \%$. Kondisi ini disebabkan proses pelaksaan program belum berjalan secara ideal, banyak mekasime, substansi dan teknis anjuran yang dilanggar oleh para pelaku di lapangan. Bukti di lapangan mengindikasikan bahwa sebanyak $42,11 \%$ responden petani mengalami kerugian, 5,26\% yang tidak mengalami perubahan terhadap sjumlah produksinya, dan hanya 52,63\% responden petani yang mengalami keuntungan usahataninya. Secara umum peningkatan produksi pertanian sesudah pelaksanaan program hanya sebesar $2,79 \%$ dan sangat jauh di bawah hasil evaluasi Bappenas yang dilakukan pada tahun 2010 terhadap pelaksanaan program revitalisasi pertanian di seluruh Indonesia yang mencapai peningkatan produksi sebesar $30 \%$.

Tabel 2. Hasil Uji Beda Rata-Rata Terhadap Jumlah Produksi Usahatani Sebelum dan sesudah Pelaksanaan Program Revitalisasi Pertanian di Daerah Penelitian

\begin{tabular}{|c|c|c|c|c|c|c|c|c|}
\hline & \multicolumn{5}{|c|}{ Paired Differences } & \multirow[b]{3}{*}{$\mathrm{t}$} & \multirow[b]{3}{*}{$\mathrm{df}$} & \multirow[b]{3}{*}{ Sig. (2-tailed) } \\
\hline & \multirow[b]{2}{*}{ Mean } & \multirow{2}{*}{$\begin{array}{c}\text { Std. } \\
\text { Deviation }\end{array}$} & \multirow{2}{*}{$\begin{array}{l}\text { Std. Error } \\
\text { Mean }\end{array}$} & \multicolumn{2}{|c|}{$\begin{array}{l}\text { 90\% Confidence Interval of } \\
\text { the Difference }\end{array}$} & & & \\
\hline & & & & Lower & Upper & & & \\
\hline air $1 \quad \mathrm{Y} 1-\mathrm{Y} 2$ & -.09053 & 1.04823 & .17005 & -.11204 & -.06901 & -.532 & & .598 \\
\hline
\end{tabular}

Sumber: Data Primer Diolah, Tahun 2017 


\section{KESIMPULAN}

\section{Rata-rata kondisi profil} kelembagaan petani di daerah penelitian dalam kondisi cukup baik ditinjau dari aspek aspek kualitas SDM, Lamanya berdiri, jenis dan status kelembagaan, bentuk organisasi, dan pola hubungannya dengan petani tanaman pangan. Kondisi profil kelembagaan petani tersebut sangat strategis untuk mendukung pelaksanaan program revitalisasi pertanian guna meningkat kinerja sub sektor pertanian tanaman pangan. Hasil evaluasi pelaksanaan program revitaliasi pertanian yang didukung oleh kondisi profil kelembagaan petani di daerah penelitian menunjukkan bahwa peningkatan kinerja sub sektor tanaman pangan hanya 2,79\% dibandingkan sebelumnya dan jika dianalisis dengan uji beda rata-rata dengan menggunakan uji t-test pada taraf nyata $10 \%$, maka peningkatan produksi usahataninya non signifikan.

\section{UCAPAN TERIMA KASIH}

Terima kasih penulis ucapkan kepada Direktora Riset dan Pengabdian kepada Masyarakat -Direktorat Jenderal Pendidikan Tinggi Kementrianristekdikti Republk Indonesia yang telah mensupport dana penelitian melalui Skim Penelitian Produk Terapan (PPT) Tahun Anggaran 2017. Dengan dukungan dana hibah ini, maka penulis dapat melakukan penelitian dan publikasi ilmiah melalui kegiatan Seminar Nasional.

\section{DAFTAR PUSTAKA}

BPS Situbondo, 2017. Kabupaten Situbondo Dalam Angka Tahun 2017. www.Berita Resmi BPS Jawa Timur. Diakses pata tanggal 16 Agustus 2017.
Ghozali, I. 2002. Aplikasi Analisis Multivariate Dengan Program SPSS. Semarang : Badan Penerbit Universitas Diponegoro.

Nazir, 1985. Metode Penelitian. Jakarta: Ghalia Indonesia.

Nurati, E., Achsani, N.A., Hafidhuddin, D., dan Nuryartono, N., 2014. Umur dan Kinerja Perusahaan: Studi Empiris Perbankan Syariah di Indonesia. Jurnal Manajemen Teknologi. 13 (2): Hal. 173 - 188 .

Peraturan Menteri Pertanian Nomor: 67/Permentan/SM.050/12/2016 tentang Pembinaan Kelembagaan Petani. www.hukumonline.com. Diakses tanggal 25 Agustus 2017

Rembang, S., 2009. Penguatan Kinerja Penyuluh Pertanian Tanaman Pangan Unggulan Kabupaten Semarang dalam Mendukung Ketahanan Pangan. https://suhadirembang. blogspot.com. Diakses Tanggal 05-08-2017.

Saptaa, Iqbal, M., dan Ar- Rozi, A.M., 2013. Evaluasi kebijakan Tujuh Revitalisasi Dalam Pembangunan Pertanian. Jurnal Analisis Kebijakan Pertanian. 11 (2): Hal. 107-1 27.

Singarimbun dan Effendi, S., 1987. Metode Penelitian Survei. LP3ES. Jakarta.

Wijaya, I., dan Hadi, S., 2017. Studi Diagnostik Pelaksanaan Program PUAP di Kabupaten Jember. Jurnal Saintek. 14 (01): Hal. 38 - 49 . 